\title{
Reading Comprehension through the FIVES Model and Guided Reading Model to Improve Critical Thinking Ability in the Industrial Revolution Era
} 4.0

\author{
Irfan Supriatna ${ }^{\bowtie 1}$, Neza Agusdianita', Nani Yuliantini' ${ }^{1}$, Herman', Resnani ${ }^{1}$ \\ 'Primary Teacher Education, Bengkulu University, Bengkulu, Indonesia \\ $\triangle$ irfansupriatna@unib.ac.id
}

\begin{abstract}
Elementary students' critical thinking skills are one of the components developed in 21 st Century learning. However, these critical thinking skills are still very shallow and far from expectations. It was proven by the results of international surveys that show low average scores. Likewise, the results of the pretest critical thinking skills of fifth-grade students in 2 elementary schools in Sukabumi Regency showed a low average value. This study aims to determine the increase in students' critical thinking skills in learning to read comprehension through the use of the FIVES Model and Guided Reading Model in the Industrial Revolution Era 4.0. The research method uses quasi-experimental with Statiq Group Pretest-Postest Design. The subject of the research was fifth-grade elementary school students. SDN 4 Cicurug implements the FIVES Model, and SDN 2 Purwas ar implements the Guided Reading Model. The results showed that the use of these two models could improve the critical thinking skills of elementary students. However, the increase in students eritical thinking skills through the FIVES Model compared to the Guided Reading Model in reading comprehension in the Industrial Revolution Era 4.0.
\end{abstract}

Keywords: Critical thinking, Reading comprehension, FIVES Model, Guided Reading Model, Industrial Revolution Era 4.0.

How to Cite: Supriatna, I., Agusdianita, N., Yuliantini, N., Herman, H., \& Resnani, R. (2020). Reading Comprehension through the FIVES Model and Guided Reading Model to Improve Critical Thinking Ability in the Industrial Revolution Era 4.0. Mimbar Sekolah Dasar, 7(1), 133-152. doi:https://doi.org/10.17509/mimbar-sd.v7i1.22500.

INTRODUCTION - Critical thinking skills are driven by higher-order thinking skills, including reasoning, analyzing, and evaluating. High-level thinking skills of students in Indonesia both based on the results of the 2018 UN and PISA 2018 still showed unsatisfactory results and even decreased compared to the results of PISA 2015. In PISA 2018 especially in reading skills, Indonesia received an average value of 371 and is ranked sixth from the bottom or ranked 74th out of 79 country (PISA, 2018).

This research is important because based on the results of PISA 2018 especially in reading skills, it is necessary to improve the quality of the learning process in the classroom, one of them is with learning models that allow children to think critically in reading.

Rezai, et.al (2011), and Leicester, M., \& Taylor, D. (2010), stated that the ability to think critically is important and as a key element a person becomes 
Irfan Supriatna et al, Reading Comprehension through the FIVES Model and Guided Reading Model ...

educated. The development of critical thinking in learning is an important and necessary goal, so there is no question about it. However, many are still questioned because in public discourse, schools are still criticized because in its implementation many students are not taught how to think critically involving various challenging stages of learning. This is evident in the results of international research which still shows figures below the average. Critical thinking has a central role in learning, because it is a student's need to be more successful both in the academic field and in real life (Fahim \& Barjesteh, 2011:2).

The ability to think critically is absolutely necessary for everyone, especially students, this is related to the skills demands demanded in the 21 st Century. 21 st Century education is education that focuses on efforts to produce young people who have four main competencies, namely thinking competency, work competency, life competence, and competence with tools for work. The 21 st Century is also marked by the many: (1) information that is available anywhere and can be accessed at any time, (2) faster computing; (3) automation that replaces routine jobs; 4) communication that can be done from anywhere and anywhere. Especially in the world of education the impact is felt now and in the future, so that people call it a period of knowledge (knowledge age) with the acceleration of an extraordinary increase in knowledge (Rahman, 2017:1).

Ennis (2012: 6) defines critical thinking as wise and sensible so that the process and its main goal is to make sensible decisions about what to believe or what to do. Opinions of some experts such as Ennis, Facione, and Elder regarding critical thinking have the same meaning, especially on aspects that explain that critical thinking is: (1) Cognitive skills such as interpreting, adding, concluding, analyzing evaluating, and making decisions according to search for information relevant and accountable; (2) the ability to develop values such as caution, humility, integrity, intellectual, and empathy (Enciso, Olga; Enciso, Diana \& Daza, Maria; 2017: 6).

Critical thinking involves a number of abilities such as the identification of problems and assumptions based on the focus of the problem, analyzing, understanding, and utilizing inductive conclusions and deductive logic, and assessing the validity and reliability of assumptions and sources of data (Rezaei, S., et al. ( 2011: 770) Critical thinking is an ability that can be developed in learning to read, especially reading comprehension, because 
in reading comprehension there are abilities that must be possessed, one of which is in critical thinking skills, which is in line with Gill's statement (Javed, M., et al. 2015: 141) which states that reading is a complex cognitive process in which the reader translates printed symbols or messages into sound, while reading comprehension is a powerful process of constructing the meaning of the text to be comprehensively understood.

To understand texts, students need to undergo certain behaviors and intellectual processes. The structuralist approach emphasizes that students must assume responsibility for learning, and participate actively in the learning process (Kirmizi, 2011: 292). Meanwhile, understanding involves building a coherent mental representation of the situation explained by the text. One of the most important skills learned by elementary students is the ability to understand written texts, which are usually referred to as reading comprehension (Barnes, et al, 2015: 253).

The activity of enjoying reading content is closely related to reading habits. During their elementary school years, children must learn not only how to read but also how to become a reader. The process of learning how to read is the initial stage of students in learning how to arrange letters, words, sentences, to the meaning of a reading. While the process of how to become a reader is an advanced stage in understanding the content of a reading. This stage is a high-level ability to understand, interpret, and even the ability to think critically (Education, Audiovisual and Culture Executive Agency (EACEA). 201 1: 7; Hobsbaum, et al. 2006: 2).

The activity of enjoying reading content is closely related to reading habits. During their elementary school years, children must learn not only how to read but also how to become a reader. The process of learning how to read is the initial stage of students in learning how to arrange letters, words, sentences, to the meaning of a reading. While the process of how to become a reader is an advanced stage in understanding the content of a reading. This stage is a high-level ability to understand, interpret, and even the ability to think critically (Education, Audiovisual and Culture Executive Agency (EACEA). 201 1: 7; Hobsbaum, et al. 2006: 2).

Based on the data of the results of the pretest, further research was conducted on learning to read comprehension in class IV Cluster 2 Purwasari Cicurug District by applying two learning models in reading comprehension in 
Irfan Supriatna et al, Reading Comprehension through the FIVES Model and Guided Reading Model ...

order to improve students' critical thinking skills. The learning model used is also allegedly able to improve the critical thinking skills of elementary students, the FIVES Model and the Guided Reading Model.

FIVES is a meaningful model in integrating learning in reading, writing, speaking, listening, seeing, developing critical thinking skills based on the text and the problems contained in the text (Nirmala, Rahman, \& Musthafa, 2017:1).

The development of critical thinking skills is marked by the development of each stage namely Facts, Inferences, Vocabularies, Experiences, and Summary. Each subsequent section of FIVES builds deeper understanding. The FIVES model is a guide to reading text processing and preparing the reader for meaningful discourse and clarifying writing activities coherently (Shea \& Roberts, 2016: 31). Hall Colby; Barnes, A. Marcia (2016); and Shea \& Roberts (2016); stated the importance of facts, inference, yocabulary, experiences, and summary, in reading learning as one step to develop critical thinking skills of elementary students.

Likewise, the Guided Reading Model is a reading learning model that is able to develop students 'understanding of reading content, develop problemsolving abilities about text content, and develop students' critical thinking skills (Nayak, G., Sylva, K. 2013: 86; Lyons, W ., \& and Thompson, SA 2012: 161; Gaffner, J., et al. 2014: 119; Fountas, Irene C., \& Pinnell, Gay S. 2013: 19). Procedures / stages of the Guided reading approach include: activities before reading, orientation to the text, reading texts, discussing about the contents of the text, and activities after reading (Long, D., \& Szabo, S., 2016: 3). Morgan, et al. (2013: 23). Morgan, et.al (2013); Ford, Michael, P. \& Opitz (2016); and Fountas, Irene C., \& Pinnell, Days S., (2013), obtained conclusions about the importance of the Guided Reading Model in reading learning.

Based on the theory and explanation above, research is focused on the analysis of critical thinking skills in learning to read comprehension through the FIVES Model and Guided Reading Model. The research questions are formulated as follows: (1) Is there an increase in students' critical thinking skills in learning to read comprehension through the FIVES Model and Guided Reading Model ?; (2) What is the description of students' critical thinking skills in reading comprehension learning through the FIVES Model and Guided Reading Model? 


\section{Critical Thinking Ability}

Dewey (Kemendikbud, 2018: 12) argues that critical thinking is essentially as an active process, in which a person thinks things through, asking questions, finding relevant information rather than waiting for information passively. Critical thinking is a process in which all knowledge and skills are mobilized in solving problems that arise, making decisions, analyzing all assumptions that arise and conducting investigations or research based on data and information that has been obtained to produce the desired information or conclusions.

The main purpose of critical thinking is to help students make correct judgments based on the heart and weigh based on available evidence (Paul, 1985, Pithers \& Soden, 2000) in Rezaei, S., et al. (2011: 770). Critical thinking can be thought of as a skill set that allows children to think deeper and clearer about what they believe (from what they read), and about what they must do. Critical thinking is important so that childrep are able to develop these skills in school because through critical learning and critical thinking is a key element in becoming someone to beeducated (Leicester, M., \& Taylor, D. 2010: 2).

Another statement related to critical thinking is delivered by Lai (2011:2), which states that criticalthinking includes the skills component of analyzing arguments, making conclusions using inductive or deductive reasoning, assessing or evaluating, and making decisions or problem solving. Background knowledge is necessary but not sufficient conditions to enable critical thinking in a particular subject. In the learning process, Quijano, (2013: 95) proposed a basic critical thinking model intended for students in grades 3 , 4 , and 5 elementary schools. The basic critical thinking model includes three categories: reading comprehension of inferential thinking, literary responses / interpretations, and concepts and structure of literary texts.

In the assessment of reading learning in class, Cubukcu, F. (2011: 12) suggests that the Bloom Taxonomy stage is a good stage in reading assessment. The best way to approach and apply critical thinking strategies and to categorize the core dimensions of reading is to use Bloom's Taxonomy: from simple to more complex stages (1-6). The dimension of thought process in Bloom's Taxonomy as perfected by Anderson \& Krathwohl (2001), consists of the ability to: know (knowing-C1), understand (understanding-C2), apply (aplyingC3), analyze (analyze-C4), evaluate (evaluate-C4), evaluate ( evaluating-C5), 
Irfan Supriatna et al, Reading Comprehension through the FIVES Model and Guided Reading Model ...

and creating (C6). According to Bloom, skills are divided into two parts. First is low level skills that are important in the learning process, namely remembering, understanding, and applying, and second are classified into higher-level thinking skills in the form of analysing, evaluating, and creating, (Kemendikbud, 2018: 11).

\section{Reading Comprehension}

Hungwe, Mbirimi-Vimbai (2016: 255), defines reading as a problem-solving process in which the reader makes an effort to understand its meaning, not only from words, but from ideas, information, claims and arguments in a text. Reading also involves more than interpreting language scripts, but it involves the reader actively engaging with the text, revealing the deeper meaning of the text, including the implied meaning and the writer's cues (Harfenik \& Wiant 2012: 79).

The most important thing from reading is understanding, and understanding is the main goal of literacy skills (Pressley, 2006; van den Broek \& Kremer, 2000) in Ness, M. (201 1: 2). Reading comprehension is a reading activity carried out by someone to comprehend the reading contents comprehensively.

Reading comprehension involves activities for remembering information from the text, extracting themes, engaging higher in thinking skills, building mental images from the text, and understanding the structure of the text. Reading comprehension is a reading activity carried out by someone to comprehend the reading contents comprehensively. Reading comprehension is done by connecting the schemata or initial knowledge that the reader has and the new knowledge gained while reading, so that the understanding process is built to its full potential. Reading comprehension is the process of acquiring meaning actively by involving the knowledge and experience possessed by the reader and related to the reading content.

Reading comprehension level consists of: (1) literal understanding, namely the ability to recognize and capture the material read explicitly stated (explicit); (2) reorganization, is the ability of the reader to analyze, synthesize or to rearrange information explicitly stated in the text; involves both quotations and summaries and paraphrases; (3) inferential understanding, i.e. the reader makes use of information explicitly stated in the text along with personal experience and prior knowledge in order to infer and form hypotheses; (4) understanding evaluation, namely the ability to compare previous 
experiences for elements in new material such as content, style, expressions, information and ideas, opinions or values of an author; and 5) Appreciation, namely the ability of the reader to articulate emotional and aesthetic responses in choosing readings according to personal standards of literary forms, styles, genres, theories, critical approaches.

One way to optimize reading comprehension skills according to Rahman (2017: 4), can be done with steps: (1) students are accustomed to reading and are provided with diverse and interesting reading material; (2) students listen to the teacher's story about the character of the story, such as by showing the cover of the story book; (3) the teacher matches the student's estimate with the contents of the reading / book; (4) students answer questions in writing; and (5) students present their writing and answers.

\section{FIVES Model}

FIVES is an acronym for Facts, Inference, Vocabulary, Experiences, and Summary. FIVES is a learning model that emphasizes the ability to read meaningful understanding to integrate learning in reading, writing, speaking, listening, seeing, developing literacy skills based on text and problems contained in the text (Shea \& Roberts, 2016: 4). The FIVES model has a clear learning scenario because it has 5 components to understand writing and text effectively. The ultimate goal of using the FIVES Model is to encourage students to engage in active reading activities that are marked by fun activities in interacting with reading texts, develop students' ability to answer complex and integrated questions, develop the ability to interpret, criticize, and evaluate text content. The steps for implementing FIVES in accordance with the acronym order are described below.

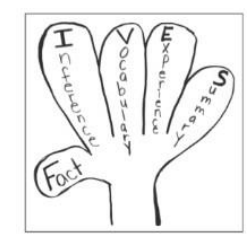

a. $F$ (Facts)

Figure 1. FIVES component

Facts are needed to get the meaning of a reading. Facts involve two cognitive functions, namely assimilation and accommodation.

Assimilation involves understanding information, the meaning of various vocabularies, and technical terms in the text. Accommodation occurs when the reader considers whether the information is consistent with what he knows 
Irfan Supriatna et al, Reading Comprehension through the FIVES Model and Guided Reading Model ...

or can be adjusted to what he knows. Students' ability to determine the facts of the reading will connect the ability to the next stage, namely inference / conclusion (Hall, Colby :; Barnes, A. Marcia, 2016: 1). The facts of the reading are outlined in the following diagram.

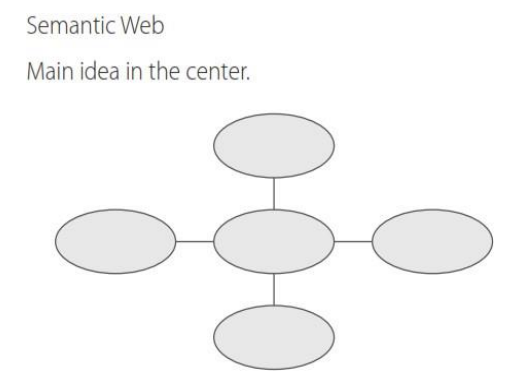

Figure 2. Diagram to explain facts

b. I (Inference)

A good reader produces conclusions based on the text and based on relevant knowledge during reading (Carlson, E. Sarah et al. 2014: 260). Inference is very important in understanding reading even in simple text, because inference allows the reader to understand information that is an integral part of understanding for a text

c. V (Vocabulary)

Words are very important, because they have power. The power between vocabulary knowledge and understanding; one's ability to understand a text is closely related to the ability to understand the meaning implied by the words of the author (Shea \& Roberts, 2016: 9). Vocabulary knowledge is a critical success factor in reading comprehension. Lack of knowledge in vocabulary can cause ehildren to be unable to process certain information which is very important for understanding the entire contents of the text. M.J. research findings Maguire et al. (2017: 6) shows that the ability to understand vocabulary in the context of reading can integrate new semantic information to predict well the overall reading content. Understanding of a vocabulary will affect the ability of students to translate the contents of the writing in discourse.

\section{d. $E$ (Experiences)}

Experiences didapatkan when readers explain, expand, evaluate, and make connections based on experience and background knowledge from everyday life. Students will find it difficult to connect reading comprehension with knowledge gained from their experiences, if the teacher does not direct 
it well. Through the FIVES Model, teachers guide students to think analytically, share ideas clearly, and make their conclusions to be used in understanding texts as a guide for developing literacy abilities.

\section{e. S (Summary)}

Summarizing is a complex layered activity process and requires explicit instruction, effective modeling, and authentic practice (Cohen \& Cowen, 2011 in Shea \& Roberts, 2016: 11). Summarizing is done by the reader by paraphrasing the content of reading through high-level thinking, it is used to find out how much the ability of readers to understand the contents of the reading. To simplify the activity of summarizing reading contents, the reader is guided using 5W + H (what, who, when, where, why + how).

\section{Guided Reading Model}

Guided reading is an important learning model in literacy education (Biddulph, J., 2002: 2). Meanwhile, Morgan, et al. (2013: 23) through the results of his research stated that the use of the guided reading approach allows teachers to appreciate the ability of each student to read. Meanwhile, the findings of a study conducted by Nayak, G., (2013: 97) showed that groups of students using the guided reading approach experienced significantly increased reading comprehension compared to groups of students who did not use the guided reading approach.

Fountas, Irene C., \& Pinnelly Gays. (2013:5) convey the stages of the guided reading approach, namely: a) the selection of the text; b) introduction to text; c) read the text; d) discussion of the text; e) learning process; f) search for vocabulary meanings, and 7) broadening understanding. Ford, Michael P. \& Opitz, Michael F. (2016: 310) suggest several characteristics of the guided reading approach, as follows:

Guided reading starts with the belief that all children have the ability to be literate. Every child is ready to learn something; (2) All children must be taught by teachers to be skilled during the guided reading stage and to maximize their full potential in reading; (3) All learning objectives provide guided reading stages to help them become independent readers as quickly as possible; (4) Children learn to read by reading; (5) reading to understand meaning is the main purpose of guided reading; (6) guided reading must help children to be metacognitive: know what they know; why and how to read; (7) Children need to experience joy and excitement as a result of their reading experience; and (8) specific elements that characterize the success of the learning phase using guided reading consisting of three parts. 
Irfan Supriatna et al, Reading Comprehension through the FIVES Model and Guided Reading Model ...

Fountas, Irene C., \& Pinnell, Gay S.(2013:5) conveys the stages of the guided reading approach, namely: (a) Text selection. The teacher chooses the right text to use in learning based on the groups that have been formed; (b) Introduction to the text. The teacher introduces the text then questions and answers about important parts of the text, for example the title, illustration illustrations, and other important parts; (c) Read the text. Students read the entire text silently. Then the teacher repeats reading parts of the text, especially parts of the text that are not understood by students; (d) Discussion of the text. The teacher invites students to discuss texts, guide discussions and raise student understanding; Teaching points. The teacher makes teaching points explicit, is based on text, and is directed towards broadening students' strategies and actions; Verbs. The teacher gives explicit teaching to help students be flexible and efficient in searching for meaning of words that are not yet understood; and broadening understanding. If further work with meaning is needed, students broaden their understanding of the text through writing and / or Figures.

\section{Industrial Revolution Era 4.0}

The era of the industrial revolution 4.0 or the fourth world industrial revolution made information technology the basis of human life. The industrial revolution 4.0 is driving the development of the Internet of or for Things followed by new technologies in data science, artificial intelligence, robotics, three-dimensional printing, and nanotechnology. One of the unique characteristics of Industry 4.0 is the application of artificial intelligence (Tjandrawinata, 2016). One form of application is the use of robots to replace human labor so that they are cheaper, more effective and efficient. Technological advancements make automation possible in almost all fields.

The education world cannot be separated from the strong influence of digital technology, including the patterns and habits of student learning (Fauzan \& Fitria, 2018). Children who attend school and higher education today are a new generation that is unique. They are Generation Z, born in mid 1990-2010. In addition to being called Generation Z or Gen Z, they are also often called digital natives, screensters, gamers, Zeds, or some are calling it part of millennial generation. Generation Z will learn more effectively if they are given "creative space" to be able to think critically, solve problems and find solutions by trial and error. Gen Z likes the challenge of learning to find, and manage the information obtained 
(Fauzan \& Fitria, 2018). Focus learning on critical thinking and problem solving instead of memorizing. information. They prefer to work in teams / small groups. Natural creativity and collaboration are right for them, whether it is spontaneous or structured activity. Strengthening the four elements that exist in the education system requires a new movement to respond to the industrial era 4.0 and facilitate millennial generation. One of the movements launched by the government is the literacy movement.

\section{METHOD}

This research was conducted in two elementary schools. While the research subjects were fourth grade elementary school students of the two schools. Learning at both schools are equally given treatment. SDN $x$ conducts learning using the FIVES Model, while SDN y uses the Guided Reading Model. Research using a quasi experiment with the Static Group Pretest-Postest Design was adapted from Mc. Millan \& Schumacher (2010:343), as shown in the following scheme.

\section{Group Pretest Treatment Postest}

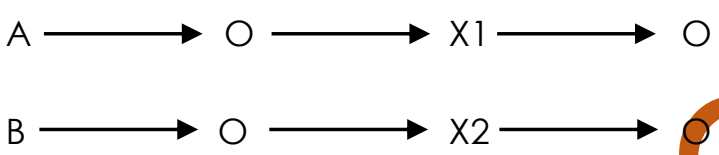

Information:

$\mathrm{O}=$ Pretest $/$ Postest

$\mathrm{X} 1=$ FIVES Model

X2= Guided Reading Mode

The expected results of research in the form of students' critical thinking skills in learning to through the application of the FIVES Model and Guided Reading Model are tested through the results of pre-test and post-test. then the instrument of critical thinking ability assessment as a parameter in this study refers to the assessment of critical thinking abilities proposed by Facione and Ennis (Kettler, Todd D., 2012), which consists of cognitive abilities: interpretation, analysis, evaluation, inference, explanation, and selfregulation. The assessment of critical thinking skills is then juxtaposed with the revised Bloom Taxonomy developed by Anderson \& Krathwohl (Munzenmaier \& Rubin, 2013), with categories of critical, low, medium, and high levels of critical thinking based on cognitive domains C4 through C6. The critical thinking assessment indicators are shown in the following table. 
Irfan Supriatna et al, Reading Comprehension through the FIVES Model and Guided Reading Model ...

Table 1. Indicators of Critical Thinking Ability

\begin{tabular}{|c|c|c|}
\hline Indicators & $\begin{array}{l}\text { Critical Thinking Assessment Sub- } \\
\text { Indicator }\end{array}$ & $\begin{array}{l}\text { Levels of Critical } \\
\text { Thinking }\end{array}$ \\
\hline \multirow[t]{3}{*}{ Interpre- tation } & $\begin{array}{l}\text { Find the implicit meaning of the } \\
\text { text }\end{array}$ & High \\
\hline & $\begin{array}{l}\text { Determine the order of text } \\
\text { information }\end{array}$ & Middle \\
\hline & $\begin{array}{l}\text { Identifying factual information } \\
\text { from the text }\end{array}$ & Low \\
\hline Analysis & $\begin{array}{l}\text { Determine information that is } \\
\text { relevant to the text }\end{array}$ & High \\
\hline \multirow[t]{3}{*}{ Evalua-tion } & $\begin{array}{l}\text { Assess the clarity / } \\
\text { completeness of the text }\end{array}$ & High \\
\hline & $\begin{array}{l}\text { Discover the application / } \\
\text { relevance of text ideas in life }\end{array}$ & High \\
\hline & $\begin{array}{l}\text { Assess the relevanc } \\
\text { content }\end{array}$ & High \\
\hline Inferen-ce & $\begin{array}{l}\text { Make text conclusionsiny } \\
\text { language }\end{array}$ & High \\
\hline \multirow[t]{3}{*}{ Explana- tion } & Find main and explanatory ideas & Middle \\
\hline & the maip sentence & Middle \\
\hline & e the causal relationship & Middle \\
\hline \multirow[t]{2}{*}{ Self- regulati-o } & $\begin{array}{l}\text { Critically respond to solutions } \\
\text { provided by the author }\end{array}$ & High \\
\hline & & High \\
\hline
\end{tabular}

\section{RESULTS AND DISCUSSION}

The results of the pretest showed that the critical thinking skills of the fourth grade elementary school students in two schools. These results are: students' critical thinking skills $84 \%$ are in the low category, $67.5 \%$ in the middle, and $52.5 \%$ in the high category. After carrying out learning to read comprehension using two models, the learning outcomes in the form of students' critical thinking skills have increased which are described next. 


\section{Differences in Students' Critical Thinking Abilities through the FIVES and Guided Reading Models}

The Improvement of students' critical thinking skills is based on the research hypothesis. "There is a difference in the ability to think critically in grade IV elementary school students in reading comprehension learning between students who take the FIVES Model and students who take the Guided Reading Model".

$$
\begin{aligned}
& H_{0}: \mu 1=\mu 2 \\
& H_{1}: \mu 1 \neq \mu 2
\end{aligned}
$$

Information $\mu 1$ = student critical thinking score in the FIVES model, $\mu 2=$ student critical thinking score in the Guided Reading Model. The output of the normality of testing data distribution using the SPSS Program is shown in the following .

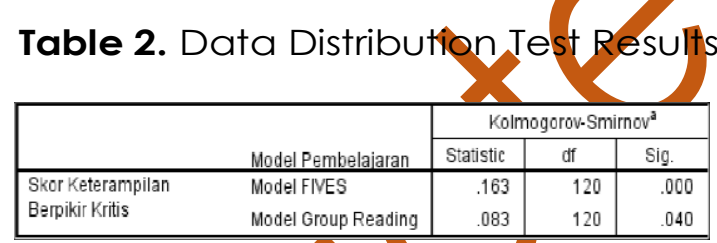

Based on Table 2, the results obtained in the FIVES Model class, p-value $(0,000)<$ $=0.05$ so that it can be said that the data is not normally distributed. In the Guided Reading Model class, p-value (0.040) $<=0.05$ so that it can be said that the data is not normally distributed. Because the data are not normally distributed, the two-means difference test will be performed using a nonparametric test, the Mann Whitney Test. The output of Mann Whitney test results using the following SPSS.

Table 3. Mann Whitney test output

\begin{tabular}{|l|r|}
\hline & \multicolumn{1}{|c|}{$\begin{array}{c}\text { Skor } \\
\text { Keterampilan } \\
\text { Berpikir Kritis }\end{array}$} \\
\hline Mann-Whitney U & 5296.500 \\
Wilcoxon W & 12556.500 \\
Z & -3.545 \\
Asymp. Sig. (2-tailed) & .000 \\
\hline
\end{tabular}

Based on Table 3, it is known that the p-value $(0,000)<x=0.05$, thus it can be concluded that the mean score of critical thinking students who take the FIVES Model (46.53) differs significantly from the average score of students who take the Guided Reading Model (43.28). The mean score of critical thinking of the FIVES Model group students was significantly greater than that of the Guided Reading Model group. Furthermore, the following graph visualizes the difference 
Irfan Supriatna et al, Reading Comprehension through the FIVES Model and Guided Reading Model ...

in the improvement of students' ability to think critically through the FIVES Model and the Guided Reading Model which are implemented in reading comprehension learning in grade IV two school.

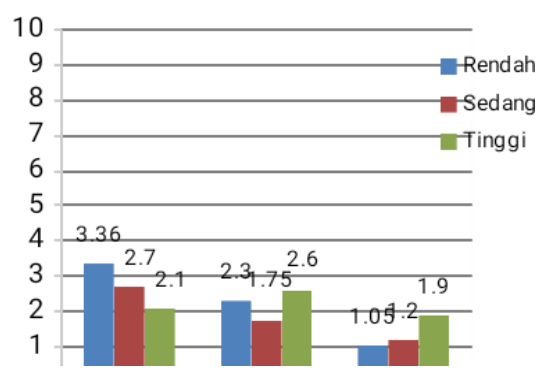

Note: Rendah=Low; Sedang=Mid; Tinggi=High

Figure 3. Graph of Increased Critical Thinking Ability

Based on Figure 3, the students' critical thinking abilities on the results of the pretest amounted to a low ability of 3.36 or $84 \%$, moderate 2.7 , and high only reached 2.1. The results of the posttest through the use of the FIVES Model of critical thinking ability of students at low leyels reached 2.3 or decreased by 26.5\%, moderate ability increased by 1.75 , and the most prominent was at high ability reaching 2.6 or increased by $65 \%$. The results of the posttest through the Guided Reading Model achieved an increase at a high level of 1.9 or $47.5 \%$, a moderate level of 1.2 or $30 \%$, and a low level that experienced a decrease of 1.05 or $26.25 \%$

Based on this, the use of the FIVES model has increased critical thinking skills greater than the Guided Redding Model, although both have increased. The superiority of students' critical thinking skills through the FIVES Model can be supported through 5 stages of FIVES.

Based on the 5 stages, students and their groups are more focused based on the five stages. In the facts stage, students focus on the facts found in the reading, giving each other input so that it makes it easier for them to determine conclusions based on these facts. This is consistent with the results of research by Hall, Colby., Barnes, A. Marcia. (2016: 1) which states that the ability of students to determine the facts of reading will connect the ability to the next stage, namely inference.

Through appropriate and complete facts, students will have more written material to make conclusions about facts. The conclusions they make are based on what they write in the fact column. This makes it easier for them 
because there are references / references based on writing rather than based on shadows.

Then in the vocabulary stage, students look enthusiastic in the use of dictionaries. Each group member scrambles to get their turn to find the meaning of words they don't yet understand. After they found it, they enthusiastically wrote it in the available column. Students' enthusiasm in understanding vocabulary will help them understand the contents of the text. This is consistent with the statement of the results of Tompkins \& Blanchfield's research (2008) in Shea \& Roberts (2016: 73), which states that there is a strong relationship between vocabulary knowledge and understanding; one's ability to understand a text is closely connected with understanding the meaning implied by the words of the author. Understanding the words of the author can be had by knowing the vocabulary of some difficult words that are not understood by children by searching through a dictionary and question and answer with the teacher. The ability to understand yocabulary makes it easier for students to understand the contents of reading which ultimately affects student literacy.

The importance of students' understanding of difficult words found in reading texts is consistent with the research findings of Catts, Fey, Tomblin, \& Zhang, 2002; Scarborough, 1998; Senechal, Oullette, \& Rodney, 2006 in (Spencer, et al. 2012: 196) which states that students who are limited in their ability to understand vocabulary will experience failure in understanding the content of reading.

Likewise the results of H.M. research Sidek \& Rahim H. Ab. (2015: 239) states that vocabulary knowledge is a critical success factor in reading comprehension. Lack of knowledge in vocabulary can cause children to be unable to process certain information which is very important for understanding the entire contents of the text. Through FIVES, students are given a special room in understanding vocabulary that they have not yet understood through the special stages of vocabulary.

Likewise in the experinces column, students have begun to have a reference in determining their experience on the topic, which is based on facts and conclusions. Based on these references, when linking topics with their experiences, students have begun to develop their ability to think critically. 
Irfan Supriatna et al, Reading Comprehension through the FIVES Model and Guided Reading Model ...

Through the experinces stage, students are given the freedom to develop their critical thinking skills by accommodating and assimilating what they get from reading by relating it to their daily experiences. This finding is also in accordance with the theory stated by Echevarria, Vogt, \& Short (2010) in Shea \& Roberts (2016: 102), that through the experinces stage, readers assimilate and accommodate and consider how new information relates their previous knowledge and experience. The teacher guides them to think analytically, share ideas clearly, and make their conclusions to be used in understanding texts and as a guide for literacy skills.

The final stage in FIVES is summary. Through this final stage students are better able to focus on the summary as the final thought of a topic. Their summary of the topic is more focused because the references are clear based on the previous stage. Based on facts, conclusions, vocabulary understanding, and student experience, at the stage of making a summary students have more basic capital in writing what is the summary. Through the four previous stages, students become more keyword reference in determining the summary, because making a summary without key words will be difficult and the summary will be less directed. This is consistent with the statement of Cohen \& Cowen (2011) in Shea \& Roberts (2016: 1), which states that concluding is a complex process of multi-layered activities that requires explicit guidance, effective modeling, and authêntic practice.

Summarizing is also a complex stage that requires students to be skilled in using communicative words and sentences. This is consistent with the results of Nuttall's (1996) research in Yu, Guoxing (2008: 521) which states that summarizing is used to compare and test communicative language because through summaries itcan be seen the use of language. This can be bridged with 4 stages of FIVES, which are able to develop communicative language for students in making summaries.

\section{Description of Students' Critical Thinking Abilities}

Critical thinking skills of students based on the results of the $84 \%$ pretest student scores are at low ability, $67.5 \%$ score on medium ability, and $52.5 \%$ on high ability. In general, students' critical thinking skills are at a low level. The posttest results using the FIVES Model, students' critical thinking skills scores generally change from low ability positions to high ability with a percentage score of $65 \%$. While the results of the posttest using the GR Model, the same has increased ie both are in high ability, only the score reached $48.7 \%$. 
From the data obtained, as well as the results of the comparison between the pretest and posttest results obtained that the use of the FIVES Model is superior in improving students' critical thinking skills compared to the GR Model. However both models have equally improved students' critical thinking skills, only the improvement score is superior to the FIVES Model.

In addition, students 'critical thinking skills through the results of the posttest using the FIVES Model, are able to develop students' critical thinking skills as stated by Leicester, M., \& Taylor, D. (2010: 7 - 65), namely the ability to ask questions, have a more critical perspective, his thinking becomes rational, has a desire to find out, and is able to analyze the facts in reading critically. The critical thinking ability of students resulting from the improvement of the learning process uses the FIVES Model as described above, which is at the C4 and C5 cognitive levels. The ability to think critically at the cognitive level according to Bloom's taxonomy as the result of Cubukcu's research, F. (2011: 12), states that the c4 level is the Analysis Level.

This level of analysis is the activity of analyzing reading content. Activities at this stage are: checking information from reading passages, analyzing character development, simplifying stories, presenting diagrams to connect characters, classifying male \& female characters, and categorizing good / bad characters.

While stage C5 is the Synthesis Level is a stage for gathering information in different ways by combining elements in patterns contained in discourse. At this stage the activities include: writing the message given, describing the relationship between two different cultures, designing plots, formulating characters, developing (restructuring events in different ways), solving problems that seem to cause problems, and rewriting stories / reading contents. Both stages of this ability have been possessed by students through learning to read integrated thematic-based understanding mainly through the FIVES Model.

From the results of this study that there is an increase in the average score of students' critical thinking skills through the use of the FIVES model and the GR model by comparing the results of the pretest and posttest. However, the score of increasing students' critical thinking skills through the use of the FIVES model is superior compared to the use of the GR model. So that 
Irfan Supriatna et al, Reading Comprehension through the FIVES Model and Guided Reading Model ...

the impact can have a significant influence on students' critical thinking skills, and from these results can be implemented in other relevant learning.

\section{CONCLUSION}

The critical thinking skills of fourth grade elementary school students in learning to read comprehension through the FIVES Model are significantly different compared to using the Guided Reading Model. The critical thinking skills of students using the FIVES Model get results (46.53) while those who follow the Guided Reading Model get results (43.28).

The difference in results reached 3.25. Based on the results of statistical tests of the implementation of learning using the two models, it can be said that the use of two learning models of reading comprehension namely the FIVES Model and the GR Model have been able to improve students' critical thinking skills.

Increased ability is seen from the average score of the ability of both students produced by the FIVES Model and the GR Model by comparing the results of the pretest and posttest. However, the score of increasing students' critical thinking skills through the use of the FIVES Model is superior compared to the use of the GR Model.

There is a difference in the increase in students' critical thinking skills through the FIVES Model compared to the Guided Reading Model in improving the critical thinking skills of fourth grade elementary school students in learning to read comprehension in Cluster 2 Purwasari Cicurug District Sukabumi District. The increase was measured based on the results of the pretest compared to the results of the students' posttests.

\section{ACKNOWLEDGMENT}

This research was supported by the two schools that accepted us to be able to conduct this research. We thank our colleagues, Neza Agusdianita, Nani Yuliantini, Herman, and Resnani, who provided insights and expertise that were very helpful in this research. We also thank the previous researchers for helping with this research methodology so that they can develop and improve this text with an update.

\section{REFERENCES}

Barnes, Marcia A., Ahmed, Y., Barth, A., \& Francis, David J. (2015). The Relation of Knowledge-Text Integration Processes and Reading Comprehension in7th- tol2th- Grade Students. in 7th- to 12th-Grade Students, Scientific Studies of Reading, 19:4, 253-272,DOI: 
m10.1080/10888438.2015.1022650.http://dx.doi.org/10.1080/10888438.201 5. 1022650

Biddulph, J. (2002). The Guided Reading Approach: Theory and Research. Learning Media Limited, Box 3293, Wellington 6001.Printed in New Zealand ISBN 0478264755 PL-9819 wwW.learningmedia.com

Carlson, E.Sarah et al. (2014). Effects ofComprehension Skill on Inference Generation during Reading. International Journal of Disability Development and Education Vol. 61, No. 3, 258-274 http://dx.doi.org/10.1080/1034912X.2014.934004

Cubukcu, F. (2011). Critical Thinking Strategies in Reading. PORTA LINGUARUM NO. 16. ISSN: 1697-746

Enciso, Olga; Enciso, Diana; \& Daza. María. (2017). Critical Thinking and Its Importance in Education: Some Reflections. Rastros Rostros/ Volumen 19/Número 34/abril (Artículo sin editar)

Education, Audiovisual and Culture Executive Agency (EACEA). (2011). Teaching Reading in Europe: Contexts, Policies and Practices. Education, Audiovisual and Culture Executive Agency P9 Eurydice Avenue du Bourget 1 (BOU2) B-1140 Brussels. ISBN 978-92-9201-1796doi:10.2797/60196

Ennis, Robert. (2012). "A Super-Streamlined Conception of Critical thinking". The Critical Thinking.http://www.criticalthinking.com/ articles/critical- thinking-definition

Fahim, M. \& Barjesteh, H. (2011). Critical Thinking: A Study of Iranian EFL Reading Comprehension Performance. Islamic Azad University, Iran. Leksika Vol.5 No.2 - Aug 201 1: 1 -9

Ford, Michael P. \& Opitz, Michael F. (2016). A National Survey of Guided Reading Practices: What We Can Learn from Primary Teachers. Literacy Research and Instruction, 47: 309-331, The College Reading Association ISSN: 1938-8071 print/1938-8063 OnlineDOI: 10.1080/19388070802332895

Fountas, Irene C., \& Pinnell, Gay s. (2013). GUIDED READING: The Romance and The Reality. The Reading Teacher Vol. 66 Issue 4 pp. 268-284 DOI:10.1002/TRTR.01 23. International Reading Association

Gaffner, J., dkk. (2014). Guided Reading in First- Fourth Grade: Theory to Practice. Texas Journal of Literacy Education Volume 2 - Issue 2 wWw.texasreaders.org ISSN 2374-7404

Hall, Colby., Barnes, A. Marcia. (2016). Inference Instruction to Support Reading Comprehension for Elementary Students With Learning Disabilities. Intervention in School and Clinic $1-8$. Reprints and permissions: sagepub.com/journalsPermissions.nav DOl: $10.1177 / 1053451216676799$

Harfenik JJ, Wiant FM. (2012). Integratingmultilingual students into college classrooms: Practical advice for Faculty. Bristol: Multilingual Matters.

Hobsbaum, A., Gamble, N., \& Reedy, D. (2006). Guiding Reading Second Edition: A Handbook for Teaching Guided Reading at Key Stage 2. The Institute of Education University of London 20 Bedford Way London WC1H OAL WWw.ioe.ac.uk/publications ISBN 085473720

Hungwe, Mbirimi-Vimbai. (2016). Translanguaging as a strategy for group work: Summary writing as a measure for reading comprehension among university students. Southern African Linguistics and Applied Language 
Irfan Supriatna et al, Reading Comprehension through the FIVES Model and Guided Reading Model ...

Studies 34(3): 241-249 ISSN 1607-3614 EISSN $1727-$ $9461 \mathrm{http}: / / \mathrm{dx}$. doi.org/10.2989/16073614.2016. 1250352

H.M. Sidek \& Rahim H. Ab. (2015). The Role of Vocabulary Knowledge in Reading Comprehension: A Cross-Linguistic Study. Procedia - Social and Behavioral Sciences 197 (2015) 50 - 56. 1877-0428 (C) 2015 Published by Elsevier Ltd. This is an open access article under the CC BY-NC-ND license(http://creativecommons.org/licenses/by- nc-nd/4.0/). doi:10.1016/j.sbspro.2015.07.046

Javed, M., Eng, Lin S., \& Mohamed, Abdul R. (2015). Developing Reading Comprehension Modules to Facilitate Reading Comprehension among Malaysian Secondary School ESL Students. International Journal of Instruction Vol.8,No.2 e-ISSN: 1308-1470 www.e-iji.netp-ISSN: $1694-$ 609XDOI: 10.12973/iji.2015.8211a

Kemendikbud. (2018). Buku pegangan pembelajaran berorientasi pada keterampilan berpikir tingkat tinggi. Jakarta: Kemendikbud

Kemendikbud. (2018). Buku pegangan Penilaian HOTS. Jakarta: Kemendikbud

Kirmizi, Fatma S. (2011). The relationship between reading comprehension strategies and reading attitudes. Education 3-13: International Journal of Primary, Elementary and Early Years Education, 39:3, 289-303,

DOI: $10.1080 / 03004270903514320$

Lai, Emily R. (2011). Critical Thinking: A Literâture Review Research Report. Pearson http://www.pearsonassessments.com/

Leicester, M., \& Taylor, D. (2010). Critical Thinking Across the Curriculum Developing Critical Thinking Skills, Literacy and Philosophy in The Primary Classroom. Open University Press McGraw-Hill Education McGraw-Hill House Shoppenhangers Roda and Two Penn Plaza, New York, NY 10121-2289, USA ISBN-13: 978-0-33-523879-8 (pb)

Lyons, W., \& and Thompson, S. A. (2012). Guided Reading in Inclusive Middle Years Classrooms. Intervention in School and Clinic 47(3) $158-166$ Hammill Institute on Disabilities Reprints and permission: http://www. sagepub.com/journals Permissions.nav

DOI:10.1177/105345/2h1423814http: isc.sagepub.com hosted at http://online.sogepub.com

McMillan, J. H., \& Schumacher, S. (2010). Research in education: evidencebased inquiry (7th ed.). Boston: Pearson.

M.J. Maguire et al. (2017). Vocabulary knowledge mediates the link between socioeconomic status and word learning in grade school. Journal of Experimental Child Psychology $x x x$ (2017) $x x x-x x x$ https://doi.org/10.1016/j.jecp.2017.10.00. 